\title{
ENCONTROS COM ALICE: \\ A PROPOSTA DE ENCONTRAR-SE COM UMA NARRATIVA
}

\section{Alissara Zanotelli* Elisangela Mara Zanelatto**}

\begin{abstract}
Resumo: Este escrito é uma narração dos Encontros com Alice. A partir da noção de narrativas em Benjamin (2012) buscou-se uma aproximação com a obra "Aventuras de Alice no País das Maravilhas", de Lewis Carroll (2009). Surge dos encontros uma conversa com o pensamento de Deleuze (2006; 1998; 1976). Nota-se que a criação destes encontros, de extensão e formação, permitiu aos participantes problematizar e narrar a matéria da vida.
\end{abstract}

Palavras-chave: encontros; narrativa; Benjamin; Carroll; formação.

Resumen: Este escrito es una narración de la actividad llamada Encuentros con Alice. La aproximación con la obra "Alicia en el país de las Maravillas", de Lewis Carroll (2009), se realizó desde la perspectiva de narrativa de Benjamin (2012). Estos encuentros propiciaron diálogos con los aportes teóricos de Deleuze $(2006 ; 1998 ; 1976)$. Se resalta que la creación de estos encuentros, de extensión y formación, permitieron a los participantes problematizar y narrar sus historias de vida.

Palabras clave: encuentros; narración; Benjamin; Carroll; formación.

\section{Do que se trata esta escrita}

Afetadas pelos escritos de Walter Benjamin (2012) e enredadas pela fascinante história de "Aventuras de Alice no País das Maravilhas" de Lewis Carroll (2009) é que nos aventuramos a compor esta escrita, alicerçada também, na experiência de encontros com possibilidades criativas. Pensar a construção da escrita sob a forma de narrativa é um desafio, especialmente por presenciarmos um momento de intensa produção e disseminação de informações.

Elegeu-se, assim, dois pontos para encontrarem-se e nessa medida, misturarem-se. Por uma via as fantasiosas aventuras de Alice em seu País das Maravilhas, e

Pedagoga; Mestranda pelo programa de PósGraduação em Ensino, do Centro Universitário Univates; bolsista Prosup/CAPES; zanotellialissara@gmail.com.

** Psicóloga; Mestranda em Ensino (UNIVATES), bolsista Prosup/CAPES; elisangelamarazanelatto@gmail.com em outro ponto os escritos de Benjamin (2012), no que se refere a narrativas. Acreditamos que os contos com princípios narrativos são possibilidades de pensar a própria experiência no cotidiano e é nesse sentido que a obra de Carroll (2009) se aproxima desta noção trazida por Benjamin (2012). Alice é uma possibilidade não apenas de devaneio, mas também de suscitar margens à leitura e abertura à imaginação da própria vida.

Sendo assim, os Encontros com Alice possibilitaram momentos de escuta de capítulos da obra "Aventuras de Alice no País das Maravilhas" (CARROLL, 2009) e de experimentações narrativas, em meio aos quais os participantes foram convidados e desafiados a embarcar em uma viagem à procura dos "coelhos brancos" que passaram por suas vidas. A partir desta provocação inicial, a experimentação narrativa foi sendo escrita e reescrita, tanto em seu sentido literal, como oralmente, pois a narrati-

Zanotelli, Alissara; Zanelatto, Elisangela Mara. Encontros com Alice: A proposta de encontrar-se com uma narrativa. Revista Sul-Americana de Filosofia e Educação. Número 30: nov./2018-abr.2019, p. 121-130. DOI: https://doi.org/10.26512/resafe.vi3o.28247 
va não requer apenas que se perpetue em seus registros alfabéticos. Tal atividade integrou a agenda de extensão do projeto Interfaces - Formação Pedagógica e Pensamento Nômade, do Centro Universitário Univates e ocorreu no período de maio e junho de 2017.

\section{Aproximações teóricas-literárias destes encontros}

Acreditamos que toda ação vem arraigada com algo que provoca movimentos no pensar e criar. Deste modo, queremos problematizar o que nos moveu teoricamente a pensar estes Encontros com Alice. Entremeio aos estudos do Mestrado, do Programa de Pós-Graduação em Ensino do Centro Universitário Univates, com apoio da CAPES (Bolsa Prosup), nos aproximamos de autores que nos afetam, sendo que seus escritos se atualizam em nossas vidas, e, possibilitam assim, questionar e até mesmo reinventar as ações do cotidiano. Para organizar o pensamento, traremos nesse trecho dois momentos, o primeiro que versa sobre a abordagem da narrativa segundo Walter Benjamin (2012) e posteriormente busca-se uma aproximação com a obra "Aventuras de Alice no País das Maravilhas" de Lewis Carroll (2009).

Começar com Benjamin é encontrálo pelo meio, por aquilo que te levanta a cabeça para refletir enquanto o lê. Assim, não traremos uma definição do que pensa o autor sobre narrativas, mas uma invenção, no sentido de tradução, a partir do que para nós, autoras deste trabalho, afeta a sua obra.
Narrar e contar nos parece a mesma coisa? Talvez possamos iniciar dizendo que narrar é contar, e contar pode ser narrar. Ou seja, querer transmitir um conto não quer dizer que ele se apresente de um modo narrativo. Para Benjamin (2012), aquele que narra não necessita explicações para seu conto, pois a narrativa não requer explicações fatigadas e aquele que ouve quanto mais "se esquece de si mesmo, mais profundamente se grava nele o que é ouvido" (BENJAMIN, 2012, p. 221).

Quando a história não vem acompanhada de uma moral, no sentido de dizer o que deve se pensar com o que se narra, ela abre a possibilidade do ouvinte fantasiar e traduzir o que ouve à experiência. E, a experiência tem relação com a narração, pois é pela experiência que o narrador cria, reconta. Ao ler e ouvir uma história, a experiência do ouvinte, que emerge na literatura, se mistura ao conto, e ao recontá-la já não é a mesma história, apesar de ser, pois o ouvinte contará o que lhe afeta. Tal experiência com a literatura é muito bem narrada por Neuscharank et al (2017, p. 4) ao dizer que,

Ler de modo que nos escapem as folhas nos gestos de tê-las nas mãos; ler e sentir um cheiro novo que saltam delas; ler em um tempo que soerguemos as palavras ao não encontrá-las, nem entendê-las, ao nos colocarmos a tatear o que desconhecemos. Quando nos arrastamos ao desconhecer o que ali está, mas que ainda assim lemos. Quando mesmo cansados e entediados, persistimos no mundo do livro que adentramos sem poder sair até terminá-lo, ainda que não tenha fim, ainda que um livro não seja a leitura que fazemos dele. Jogatina de visões, disparo de 
mundos, composições infinitas, ao fazer dele nascimento de alguma coisa, (trans)formação, saída de formas.

Sendo assim, mesmo que o narrador utilize as mesmas palavras, algo de singular escapa, acontece e é nestas miudezas de singularidade que tornará a história uma narrativa. Nesse sentido, a explicação "é substituída pela exegese, que não se preocupa com o encadeamento exato de fatos determinados, mas com a maneira de sua inserção no fluxo insondável das coisas" (BENJAMIN, 2012, p. 226). Com isso, podemos pensar que uma narração também se configura como conselho, e nessa ótica, Gagnebin (2013) nos apresenta alguns elementos para problematizar a narrativa.

O conselho só pode ser, portanto, dado se uma história conseguir ser dita, colocada em palavras, e isso não de maneira definitiva ou exaustiva, mas pelo contrário, com as hesitações, as tentativas, até as angústias de uma história 'que se desenvolve agora', que admite, portanto, vários desenvolvimentos possíveis, várias sequências diferentes, várias conclusões desconhecidas que ele pode ajudar não só a escolher, mas mesmo a inventar, na retomada e na transformação por muitos de uma narrativa à primeira vista encerrada na sua solidão (GAGNEBIN, 2013, p. 63).

Um conto que apresenta a possibilidade de desenvolver-se de outros modos, de apresentar outras sequências e não apenas o final já dito, pode considerar-se uma narrativa. Mas para que isso aconteça é preciso atenção ao desenrolar de um conto. Aten- ção ao que o conto quer nos dizer e o quanto ele pode abrir margens à fantasia. Embora a narrativa não requeira explicações fatigadas e este texto poderia se considerar um modo de narrar, é preciso perguntar: O que nos leva a aproximar a obra "Alice no País das Maravilhas” (CARROLL, 2009), e entender que esta aproximação pode ser chamada de encontros?

Em princípio se faz necessário dizer que os encontros acontecem no presente, eles não têm intenções definidas anteriormente, apesar de existir um planejamento. Nestes encontros “o que é importante não são nunca as filiações, mas as alianças e as ligas; não são os hereditários, os descendentes, mas os contágios, as epidemias, o vento" (DELEUZE; PARNET, 1998, p.83). Assim, no encontro com Alice o importante foram os contágios que com ela pudemos realizar. Encontros-acontecimentos, em que longe de procurar significados, o que se pretende é narrar o vivido. Para Deleuze (200o, 1974, p. 34) quando se fala em acontecimento, não está em jogo os sentidos, pois "o acontecimento é o próprio sentido".

À vista dessas considerações, acredita-se que a obra de Lewis Carroll (2009) pode ser considerada atemporal, pois escrita em 1832, ainda se atualiza no nosso cotidiano, sendo utilizada tanto para pesquisas acadêmicas (AMORIM, 2005; SALGADO, 2012) como para apreciação em contos de cabeceira. Mas o que a torna tão atual? Alice não traz em seus escritos um final que diga o que deve ser sua história. Por ser um conto non sense (MONZANI, 2011) possibilita um afastamento do cotidiano rotineiro e permite ao leitor e ouvinte fantasiar, recriando a sua própria realidade. 
[...] o autor de Alice vai exatamente contra essa moral única: ele brinca com conceitos, demonstra através de jogos linguísticos e lógicos que algumas das consistências que acreditamos encontrar não são senão imposições que nós mesmos colocamos, destruídas pelas próprias palavras. É, em outros termos, o elemento que o deixou reconhecido como inovador, o non sense (MONZANI, 2011, p. 125).

Carroll (2009) brinca com as palavras, permitindo invenção. As palavras estão para uso, não sendo apenas o leitor que precisa debruçar-se sobre ela, tornando-se escravo do que lê. Em primeira vista, o sem sentido pode parecer algo que não cabe na lógica de pensar as histórias. Mas, como já mencionamos, é justamente o acontecimento, o agora, que gera o sentido na obra, tornando-a uma forma de narração.

[...] A obra de Lewis Carroll tem tudo para agradar ao leitor atual: livros para crianças, de preferência para meninas; palavras esplêndidas, insólitas, esotéricas; crivos, códigos e decodificações; desenhos e fotos; um conteúdo psicanalítico profundo, um formalismo lógico e linguístico exemplar (DELEUZE, 1974, Introdução).

Como nos diz Deleuze (1974), Lewis Carroll tem a grandeza de nos presentear com imaginação, com a possibilidade de reconstruir e repensar nosso cotidiano com Alice. A menina apenas narra suas aventuras, e nesta narração ela ainda imagina. Como podemos perceber, no capítulo I (CARROLL, 2009, p. 13-22), em que ela se joga pela toca do coelho, e não é possível imaginar quanto tempo ela passa caindo, nem o espaço percorrido, mas ali coisas estavam acontecendo e sendo observadas. Nessa travessia, chama atenção de Alice, dentre tantas coisas, os vidros de geleia armazenados em prateleiras. Poderia um túnel conter vidros de geleia? E em guardalouças? Este túnel caía em que direção? Assim, percebemos que a história conta, e nada mais que isso. Ela convida, deixa que os apreciadores façam dela o que desejarem.

\section{O que se passou}

Os Encontros com Alice aconteceram em quatro momentos junto à Brinquedoteca do Centro Universitário Univates, e tiveram aproximadamente uma hora de duração cada. No entanto, não podemos calcular o quanto a vivência de cada encontro se manteve ressoando em cada participante. A escolha do local - a brinquedoteca - veio pela possibilidade de um outro encontro: com o lúdico. Estar na brinquedoteca permitiu aos participantes respirar em meio a um ambiente que convida à imaginação, na medida em que ela proporciona a criação do próprio cenário, ou seja, escolher onde sentar, se cadeira ou poltrona, chão ou almofadas, sendo que assim o cenário se constitui diferente em cada encontro.

Encontro 1 - Alguém viu o Coelho Branco?

No primeiro encontro, quem chegou para encontrar Alice, encontrou mais. Cada participante, de alguma maneira, encontrou a possibilidade de poder se reencontrar junto com Alice, o que surgiu quando cada um 
se apresentou ao grupo. As expectativas em relação a esta proposta foram sendo contadas e observou-se que o que os levou até os encontros foi a curiosidade de compreender como a obra "Aventuras de Alice no País das Maravilhas” (CARROLL, 2009) poderia auxiliar na compreensão da escrita narrativa. Do mesmo jeito, outra motivação percebida mostrou a vontade de escutar a narração desta história, comentada pelo grupo, aleatoriamente, como sendo "uma daquelas que nunca foi esquecida", especialmente pelo seu tom imaginativo, sem ordem de acontecimentos e marcado pela surpresa.

Após realizarmos a narração do primeiro capítulo da história: "Pela toca do Coelho" (CARROLL, 2009, p. 13-22), foi proposto um momento de comentários sobre a vivência. E, como forma de resgatar alguns elementos da narrativa, frases do capítulo I (CARROLL, 2009, p.13-22), foram impressas e expostas ao chão e no centro da roda, a fim de atuarem como disparadores de diálogo, resgatando alguns momentos da história de Carroll (2009) narrada anteriormente, tais como: "De que serve um livro? pensou Alice, 'sem figuras nem diálogos'?" (p.13); "Ai, ai! $\mathrm{Ai}$, ai vou chegar atrasado demais!" (p. 13); “[...] a vida seguisse de maneira habitual” (p. 13); “[...] quando viu um coelho tirar um relógio do bolso do colete e sair em disparada, e ardendo de curiosidade correu pela campina atrás dele" (p. 13-14); "[...] sem nem pensar de que jeito conseguiria sair depois” (p. 14); “Ou o poço era muito fundo, ou ela caia devagar, porque enquanto caia teve tempo de sobra para olhar a sua volta e imaginar o que iria acontecer em seguida" (p. 14); "Para que latitude, longitude estou indo?” (p. 15); “[...] experimentou cada porta” (p. 17); "Como não estava escrito veneno Alice se arriscou a provar [...] Que sensação estranha" (p. 2o); "De uma maneira ou de outra vou chegar no jardim” (p. 21).

Assim, cada um escolheu um trecho, aquele que de algum modo mais lhe afetou, que mais lhe despertou interesse, para dialogar com os demais participantes. Em seguida, e como fechamento do encontro 1, o grupo foi convidado a pensar e narrar (escrevendo) a partir da seguinte provocação: Quais foram os coelhos brancos que passaram por mim?

Encontro 2 - Que tipo de conselho uma lagarta pode dar?

No segundo encontro, o momento inicial foi marcado pala retomada do encontro anterior, tentando pensar sobre o conto que foi narrado, e o que a Alice experimentou desde que viu o Coelho Branco. Na sequência, foram distribuídos alguns fragmentos do texto "O Narrador" de Walter Benjamin (2012), e em duplas a leitura foi realizada. Estes trechos serviram como estímulos, a fim de pensar o conceito de narrativa a partir do autor proposto. Pois, o que são narrativas? O que as caracterizam? Como pensar a vida de um modo narrativo? Para o fim do segundo encontro, foi contado o capítulo do livro "O conselho de uma Lagarta” (CARROLL 2009, p. 55-66).

Encontro 3 - Você tem tempo para um chá?

No terceiro encontro, a narração do capítulo "Um Chá Maluco" (CARROLL, 2009, p 80-91) foi proposta de forma coletiva. Assim, cada participante recebeu uma 
cópia da história e os personagens descritos nesta foram escolhidos pelos presentes. A ideia de narrar coletivamente, surgiu na perspectiva de experimentar o lugar de narrador e ao mesmo tempo de ouvinte. Esta experiência foi descrita pelo grupo como provocadora, na medida em que instiga o narrador a se transportar/transmutar para o lugar do personagem. Imbuídos em meio as às sensações desta vivência, cada um foi convidado a entrar em contato com a narrativa construída no primeiro dia, e nesse sentido, reescrevê-la ou ampliá-la, levando em consideração, as discussões realizadas até o momento.

Encontro 4 - Será que o chá maluco foi apenas repetido?

Para o quarto e último encontro, o capítulo "Um Chá maluco" (CARROLL, 2009, p 80-91) foi retomado. A escolha em repeti-lo, revisitá-lo se explica na intensidade dos elementos narrados que afetaram o grupo, em especial a ideia de tempo e de repetição. Na tentativa de possibilitar novas experimentações, a narração foi realizada no formato de dramatização. Os personagens foram novamente redistribuídos entre o grupo, e cada um pode construir o seu a partir de elementos/materiais disponíveis na brinquedoteca, tais como roupas e adereços. Inicialmente notou-se um estado de surpresa nos participantes, que aos poucos deu lugar ao desejo de ocupar a posição da figura que representariam. Cada um, de acordo com suas particularidades imaginativas, construiu seu personagem. A maioria desconstruiu as imagens caricaturizadas, fazendo surgir novos-mesmos personagens, como uma proposta de invenção e criação, permitindo que também a produção cenográfica dos personagens fosse uma forma de narrar, segundo o conceito que o grupo vinha pensando nos encontros. Nessa perspectiva, quando a narradramatização ${ }^{2}$ iniciou foi possível perceber um misto de desconforto, alegria e ansiedade diante da experimentação de narrar um conto na perspectiva de construção com o outro. Ao longo deste encontro, nos parece que aos poucos os novos-mesmos personagens foram se anunciando como tais e se misturando com a história.

No final da narradramatização, o grupo foi inesperadamente interrompido por um pote fechado, com algo dentro, e do grupo foi retirada a cópia do texto que auxiliava a narração. Sendo assim, os personagens deveriam continuar a história com este novo elemento em cena. Retomaram o chá maluco, demonstrando o aceite do desafio lançado. Talvez, neste instante, o ápice do ensejo de se encontrar com Alice tenha acontecido. Deparar-se com o inusitado, com o estranho, com aquilo que não conhece um significado, mas múltiplos, parece ter surgido naquele instante, e permitindo que essa brecha possa ser vivida como uma possibilidade de inventar a si e a outro no mesmo tempo. No término deste momento, os participantes ainda em estado de transição do personagem, puderam narrar-se,

\footnotetext{
${ }^{2}$ Palavra construída pelas autoras na tentativa de compor e contemplar a ideia de narração vivenciada pela expressão do corpo como um todo, na amplitude de gestos, entonação de voz e performance corporal. Entendida como experiência singular que ocorre no coletivo, em meio as surpresas do encontro com as possibilidades inventivas e particulares do outro, do grupo.
} 
contando tanto a vivência de atores como de ouvinte. Logo em seguida, o último encontro foi encerrado com um espaço em que cada um pode falar sobre o seu Encontro com Alice.

No percurso inaugurado a cada encontro, acreditamos que de alguma forma, nos transformamos. Assim, como na narradramatização os personagens foram construídos, cada um experimentou de maneira particular as afetações que a narração dos capítulos de "Aventuras de Alice no País das Maravilhas” (CAROL, 2009) possibilitou. Do mesmo modo que esta obra nos convocou a pensar e viver o instante do acontecimento, nos provocou também a fazê-lo na dimensão da multiplicidade, despertando para o movimento, para que outros agenciamentos pudessem acontecer. Para Neuscharank et al (2017, p. 5) tais afetações possibilitam pensar a potência encontrada na experiência literária, que permite a invenção de outros modos de pensar, de experimentar, de existir, de "nos dissolvermos no mundo, sairmos das formas, rachar a nós mesmos: um corpo que não investe em viver um interior separado do exterior [...]".

Assim, o fato do capítulo "Um Chá Maluco" (CARROLL, 2009, p 80-91) ser revisitado, narrado por duas vezes, pode nos indicar a intensidade e ao mesmo tempo, a necessidade de experienciar novamente alguns elementos, nos conduzindo à repetição. Sobre isto, o grupo se sentiu motivado a pensar: como mesmo na repetição do momento do chá maluco (e talvez é por isso que foi nomeado como maluco) a diferença se fez presente? Acerca de tais considerações, sem demora, somos invadidos pelas ideias de Deleuze (2006), de modo especial, no seu livro "Diferença e repetição" (2006), na medida que nos permite visualizar a repetição como um movimento a ser criado, no qual o autor comenta que, "repetir é comportar-se, mas em relação a algo único ou singular, algo que não tem semelhante ou equivalente" (p. 20).

Tal fato foi percebido e sentido, de maneira notável na criação de estratégias dos personagens que estavam aprisionados no momento do chá maluco. E, para vivenciá-lo ou resistir a ele, a solução residiu na invenção de outros modos de estar lá, como trocando de lugares. Sendo assim, a repetição mostra uma potência de criação, e sugere ser tecida num complexo entrelaçamento de forças. Em meio a tudo aquilo que já é, que já está determinado e ao mesmo tempo, convive com a multiplicidade, com a heterogeneidade, com aquilo que pode vir a ser, a diferença. Acerca desses elementos, Deleuze (2006) vem dizer que,

[...] se a repetição pode ser encontrada, mesmo na natureza, é em nome de uma potência que se afirma contra a lei, que trabalha sob as leis, talvez superior às leis. Se a repetição existe, ela exprime, ao mesmo tempo, uma singularidade contra o geral, uma universalidade contra o particular, uma eternidade contra a permanência. Sob todos os aspectos, a repetição é a transgressão. Ela põe a lei em questão, denuncia seu caráter nominal ou geral em proveito de uma realidade mais profunda e mais artística (DELEUZE, 2006, p. 21).

Pensamos assim, que a diferença que se fundou na repetição do chá maluco, mostrou-se como um movimento de estímulo, 
ligado a criação, a imaginação, e não um movimento de representação. Como afirma Deleuze (2006) o movimento que é produzido em uma obra tem a necessidade de conseguir "comover o espírito fora de toda representação; trata-se de fazer do próprio movimento uma obra, sem interposição; [...] de inventar vibrações, rotações, giros, gravitações, danças ou saltos que atinjam diretamente o espírito" (p.29).

Diante da experiência da narradramatização do chá maluco, talvez, o movimento se fez obra, na medida em que se tornou real enquanto acontecimento vivido, como declara Deleuze (2006, p. 29) "o teatro é o movimento real [...]. Eis o que nos é dito: este movimento, a essência e a interioridade do movimento, é a repetição, não a oposição, não a mediação". E, segundo os participantes, foi um momento sentido, experimentado pelo atravessamento de intensas e inúmeras forças, sensações, que provocaram, instigando-os à viver o personagem, de uma forma outra, e não apenas representá-lo, mas recriá-lo, na medida em que o capítulo era repetido e o cenário era surpreendido por forças externas (como a retirada das cópias do texto e a inserção de objetos). Em relação à dramatização e o que foi produzido por ela, encontramos novamente, em Deleuze (2006), considerações importantes sobre o teatro como movimento, repetição,

Quando, ao contrário, se diz que o movimento é a repetição e que é este nosso verdadeiro teatro, não se está falando do esforço do ator que "ensaia" enquanto a peça ainda não está pronta. Pensa-se no espaço cênico, no vazio deste espaço, na mesma maneira como ele é preenchido, determinado por signos e máscaras por meio dos quais o ator desempenha um papel que desempenha outros papéis; pensa-se como a repetição se tece de um ponto notável a um outro, compreendendo em si as diferenças (DELEUZE, 2006, p. 30-31).

Suspeitamos que tais afetações foram oportunizadas pelo (re)encontro com a permanência da mudança, da imaginação e a atemporalidade dos acontecimentos que encontramos na obra "Aventuras de Alice no País das Maravilhas" (CARROLL, 2009). Escrito que de alguma forma nos permite visualizar, experimentar paradoxos da existência, como este da diferença que acontece na repetição do "chá-maluco", ou mesmo, na possibilidade de não saber quem se é mesmo sabendo, como se vive junto com Alice no seu encontro com a Lagarta.

Contudo, chegar ao final dos Encontros com Alice parece não marcar um encerramento, ao contrário, sugere tantas outras possibilidades de iniciar. Possibilidades que podem nos permitir outras maneiras de existir no mundo, e, quem sabe, possam nos aproximar de nós mesmos. Também nos permite entender que, por vezes, é preciso se encontrar, permitir o encontro, sem que este seja definido por tarefas determinadas.

\section{Considerações}

Construir os Encontros com Alice, foi uma possibilidade criativa de aproximar o estudo da escrita narrativa na perspectiva de Walter Benjamin (2012) a uma obra literária extremamente potente, como se mos- 
tra "Aventuras de Alice no País das Maravilhas", de Lewis Carroll (2009). Mas, arriscase que o maior encontro, (e talvez nem mesmo as propositoras destes Encontros com Alice poderiam imaginar) é que os encontros foram se construindo na complexa trama de singularidades e multiplicidades do coletivo que ali se estabeleceu.

Narrar, contar e experienciar Alice por meio dos encontros se mostrou uma proposta que chamou a atenção, e que provocou novos movimentos. Poderíamos imaginar que um coelho branco, de olhos cor- de-rosa, passou e despertou em algumas pessoas a curiosidade de segui-lo. E assim como Alice, suspeitamos que o coelho possa novamente aparecer, por isso atentamos para a importância de ficar de olhos bem abertos e não perder a oportunidade de segui-lo e deixar-se, permitir-se experimentar o que oferece um encontro.

Neste sentido, os encontros poderão seguir, talvez não somente com Alice. No intuito de atentar aos coelhos brancos, é que outros encontros se abrem, e desta vez nos Encontros com Dorothy.

\section{Referências}

AMORIM, Lauro Maia. Tradução e adaptação: encruzilhadas da textualidade em Alice no País das Maravilhas, de Lewis Carroll, e Kim, de Rudyard Kipling. UNESP, 2005.

BENJAMIN, Walter. Magia e Técnica, arte e política: ensaios sobre literatura e história da cultura. Tradução de Sérgio Paulo Rouanet. 8a Ed. Obras Escolhidas vol. ı. São Paulo: Brasiliense, 2012.

CARROLL, Lewis. Aventuras de Alice no País das Maravilhas. In: CARROLL, Lewis. Alice: Aventuras de Alice no País das Maravilhas e Através do Espelho e o que Alice encontrou por lá. Rio de Janeiro: Zahar, 2009.

DELEUZE, Gilles; PARNET, Claire. Diálogos. Tradução de Eloisa Araújo Ribeiro. São Paulo: Editora Escuta, 1998.

. Diferença e repetição. Rio de Janeiro: Graal, 2ª edição, 2006.

. Lógica do Sentido. São Paulo: Perspectiva: 1974.

GAGNEBIN, Jeanne Marie. História e narração em Walter Benjamin. São Paulo: Perspectiva, 2013. 2 ed.

MONZANI, Luiz Henrique. Deleuze e Lewis Carroll: aproximações entre filosofia e literatura. Kínesis - Revista de Estudos dos Pós-Graduandos em Filosofia, v. 3, n. o6, dez. 2011, p. 123136. 
NEUSCHARANK, Angélica; DALMASO, Alice Copetti; BARIN, Ana Claudia; OLIVEIRA, Marilda Oliveira de. Leitura, literatura e docência: encontros com signos, devir e fabulação. Revista Sul-Americana de Filosofia e Educação, n 27, nov. 2016 - abr. 2017, p. 4-18.

QUINTINO, Tania Cristina de Assis. Alice no país das maravilhas: currículo integrado, interdisciplinaridade, e um grupo de professores que mergulha na toca do coelho. 2005. $156 \mathrm{f}$. Dissertação (Mestrado em Educação) - Faculdade de Educação, Universidade Estadual de Campinas (UNICAMP), Campinas, SP. 2005. Disponível em:<http://repositorio.unicamp.br/bitstream/REPOSIP/25218o/1/Quintino,\%2oT\%3Fnia\%20 Maria\%2ode\%2oAssis.pdf> Acesso em: 28 jun. 2017.

SALGADO, Fernanda de Cássia Alves. Cinematografias do fantástico: visões de Alice e do país das maravilhas no cinema. 2012. 179 f. Dissertação (Mestrado em Artes) - Faculdade de Belas Artes, Universidade Federal de Minas Gerais. Belo Horizonte. 2012. Disponível em:<http://hdl.handle.net/1843/JSSS-8ZZJE5> Acesso em: 28 jun. 2017.

Recebido em: $14 / 07 / 2017$ Aprovado em: 31/10/2019 